\title{
Capability of Multi-Material Laser-Based Powder Bed Fusion-Development and Analysis of a Prototype Large Bore Engine Component
}

\author{
Matthias Schneck (D), Max Horn *(D), Maik Schindler (D) and Christian Seidel \\ Fraunhofer Institute for Casting, Composite and Processing Technology IGCV, Am Technologiezentrum 10, \\ 86159 Augsburg, Germany; matthias.schneck@igcv.fraunhofer.de (M.S.); maik.schindler@gmx.com (M.S.); \\ christian.seidel@igcv.fraunhofer.de (C.S.) \\ * Correspondence: max.horn@igcv.fraunhofer.de; Tel.: +49-821-90678-187
}

check for updates

Citation: Schneck, M.; Horn, M.; Schindler, M.; Seidel, C. Capability of Multi-Material Laser-Based Powder Bed Fusion-Development and Analysis of a Prototype Large Bore Engine Component. Metals 2022, 12, 44. https://doi.org/10.3390/ met12010044

Academic Editors: Katrin Wudy and Peter Mayr

Received: 16 November 2021 Accepted: 20 December 2021 Published: 25 December 2021

Publisher's Note: MDPI stays neutral with regard to jurisdictional claims in published maps and institutional affiliations.

Copyright: (c) 2021 by the authors. Licensee MDPI, Basel, Switzerland. This article is an open access article distributed under the terms and conditions of the Creative Commons Attribution (CC BY) license (https:// creativecommons.org/licenses/by/ $4.0 /)$.

\begin{abstract}
Additive Manufacturing (AM) allows the manufacturing of functionally graded materials (FGM). This includes compositional grading, which enables the allocation of desired materials corresponding to local product requirements. An upcoming AM process for the creation of metal-based FGMs is laser-based powder bed fusion (PBF-LB/M) utilized for multi-material manufacturing (MM). Three-dimensional multi-material approaches for PBF-LB/M are stated to have a manufacturing readiness level (MRL) of 4 to 5. In this paper, an advancement of multi-material technology is presented by realizing an industry-relevant complex part as a prototype made by PBF-LB/M. Hence, a multi-material injection nozzle consisting of tool steel and a copper alloy was manufactured in a continuous PBF-LB/M process. Single material regions showed qualities similar to the ones resulting from mono-material processes. A geometrically defined transition zone between the two materials was achieved that showed slightly higher porosity than mono-material regions. Nevertheless, defects such as porosity, cracks, and material cross-contamination were detected and must be overcome in further MM technology development.
\end{abstract}

Keywords: laser-based powder bed fusion; PBF-LB/M; multi-material; functionally graded materials; powder deposition; copper; steel

\section{Introduction}

The objective of this paper is to demonstrate an advancement in multi-material manufacturing (MM) by laser-based powder bed fusion (PBF-LB/M) technology, as defined in ISO/ASTM 52900 [1]. The current state of three-dimensional, metallic multi-material structures manufactured by PBF-LB/M is believed to be at manufacturing readiness level (MRL) of 4 to 5 [2]. At this maturity level, a technology is demonstrated in a laboratory environment, including processes sufficient to produce technology demonstrators (compare definition of MRL scale in [3]).

Based on the PBF-LB/M process characteristics, a three-dimensional MM structure is defined as a structure with "material transition [s] in at least two dimensions" or, equally, as a structure with "material transition [s]) between and within layers" [2,4]. Considering the material combinations that are utilized for MM structures, it is found that

- metal-metal combinations are investigated in eleven publications, especially aluminum-copper [4], steel-nickel [5], and steel-copper [4-14]; moreover,

- metal-non-metal combinations are investigated in five publications, especially copper with ceramics [10] or glass [15], steel with WC-Co [16], ceramics [10,17], or glass [15]. 
Based on the literature review, it can be stated that the most investigated material combination for MM is steel combined with copper alloys. The material properties of steels merged with copper alloys make this a suitable material combination for applications where increased heat dissipation is needed in highly stressed components, such as the case investigated in this study (see: Figure 1). In order to evaluate the processability and occurring defects, the metallurgical basics of the material combination's base alloys, as well as results from previous MM PBF-LB/M investigations, are summarized in the following paragraphs.

The Fe-Cu binary system exhibits a peritectic reaction for the Fe-rich side, a flat liquidus line, and full solid-state immiscibility. Up to 11 weight percent (wt.\%) of $\mathrm{Cu}$ can be dissolved in $\gamma-\mathrm{Fe}$, which shows the highest solubility, at roughly $1450{ }^{\circ} \mathrm{C}$. Cu can be an alternative to nickel to support austenite creation [18]. Liquid-phase separation that occurs during rapid solidification processes, however, is the most relevant effect for welding processes. The liquefied material mixture separates into dispersed droplets of both components. Depending on the element concentration and cooling rates, secondary and tertiary phase separation can occur, leading mainly to the presence of discrete Ferich and $\mathrm{Cu}$-rich zones. This effect is also used to increase the mechanical properties of stainless steel 1.4542 and other chromium-nickel-copper steels through precipitation of the face-centered cubic (fcc) $\varepsilon$-Cu phase [19-23]. The fusion zones of dissimilar metal joints of most steels with $\mathrm{Cu}$ alloys manufactured by laser welding also exhibit the presence of discrete $\varepsilon-\mathrm{Cu}$ and $\gamma$-Fe or $\alpha$-Fe zones, respectively. Furthermore, the accumulation of liquefied copper along the already solidified grain boundaries of the steel materials can lead to hot cracking [20,21,24,25]. This has also been shown in PBF-LB/M for tool steel 1.2709 contaminated with copper alloy particles [26].

The advantage of and motivation to produce multi-materials by additive manufacturing is to generate a functionally graded material —in particular, to create a part-which utilizes different metals as required by a local material specification $[27,28]$. The use and benefits of PBF-LB/M to create such functionally graded materials have been discussed in the literature [29,30]. Considering the approaches for multi-materials by PBF-LB/M, they can be categorized into two types: the first is an approach where the material change is only in the build direction (two-dimensional, 2D), and the other allows for three-dimensional structures in which the direction of material change is independent of the build direction (three-dimensional, 3D). A structure with a 2D material transition between steel and copper building on a conventional material and adding an additive one has been demonstrated by Tan et al. [31], Santos et al. [32], Wallis et al. [33], and Yeong and Chen [34]. Investigations of a 2D material transition between two additively build materials have also been performed by Chen et al. [35], Chueh et al. [36,37], and Liu et al. [38]. However, three-dimensional material transitions for steel and copper have also been reported before $[4,5,10,11,39]$. In this research, powder deposition of different materials is managed by a nozzle concept or a holohedral suction device. The focus of the existing literature is mainly on the development of appropriate powder deposition devices for multi-materials and the investigation of the material combination based on simple test geometries such as cubes. In the reviewed literature, there are no industry-relevant complex geometrical parts presented. Thus, this case report aims to investigate the capabilities and shortfalls when manufacturing an industry-relevant multi-material part by PBF-LB/M.

An injection nozzle was selected as a prototype component to demonstrate the capabilities of MM technology. The injection nozzle is a core component of combustion engines, crucial for the efficiency of the burning process [40]. A general design of an injection nozzle, based on [41], is depicted in Figure 1. The injection nozzle must fulfill thermal and mechanical requirements. Since the tip of the injection nozzle is located within the burning chamber of the engine, it is, in particular, exposed to cyclic thermal loads. Mechanical loads are caused by the pressure of the fuel and the sealing against this pressure level, especially at the needle seat. Cooling of an injection nozzle is an established practice; however, space in the nozzle tip for cooling channels is limited. Furthermore, small cooling channels have 
only limited capacity for energy dissipation. Thus, a nozzle with optimized heat flow was designed and additively manufactured by utilizing a PBF-LB/M multi-material process.

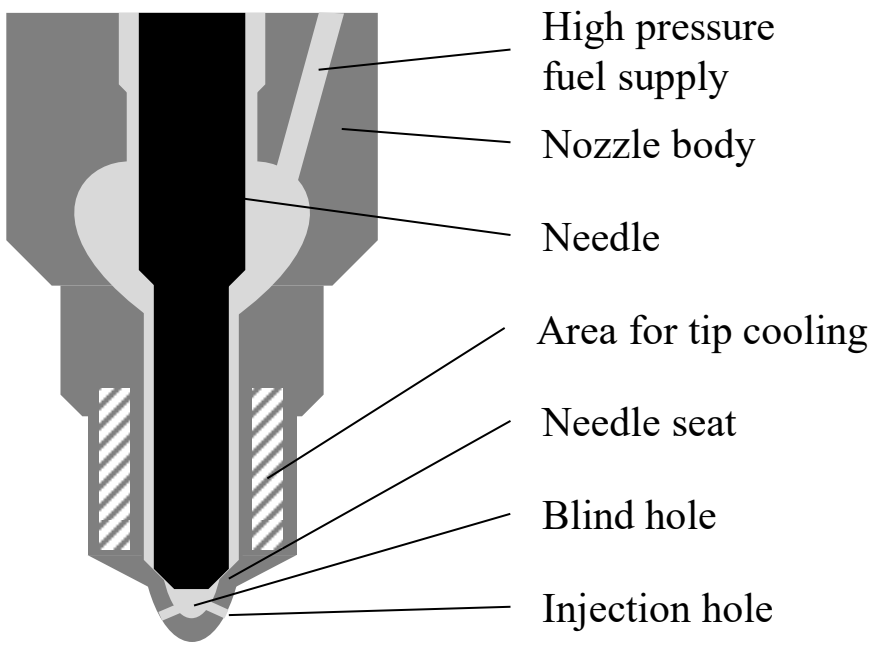

Figure 1. Design of an injection nozzle, based on Zeh and Okumuşoğlu [41].

\section{Method, Materials, and Component Manufacturing}

To manufacture the prototype component by PBF-LB/M, prior multi-material approaches that have demonstrated applicability on simpler geometries and demonstrator parts [42-44] were utilized. At first, a CAD model of the MM injection nozzle was created in Siemens NX. The MM nozzle design was developed in close cooperation with experts in injection systems. Instead of cooling channels, a copper inlet for improved heat transfer was designed at the nozzle tip. The copper inlet can maximize the covered volume area in the tip, but, due to the mechanical loads, it must be contained in a shell of steel. Tool steel 1.2709 and the copper alloy CW106C were chosen as the materials. The overlap between the steel and copper area was defined to be $400 \mu \mathrm{m}[4,13]$.

The build job was created from the CAD model. Therefore, separate models were derived for each material [2]. Thus, the steel body volume and the copper inlet volume were exported as STL files. The data preparation for MM requires separate processing of each material volume and, finally, virtual assembly of the MM part in the build job file [39]. Hence, the STL models of each material were positioned according to the desired material allocation in the final part. Two MM nozzles were nested on the build plate (see Figure 2a), and then sliced and converted to the proprietary SLM file format using AutoFab computeraided manufacturing (CAM) software from Marcam Engineering, Bremen, Germany.

a)

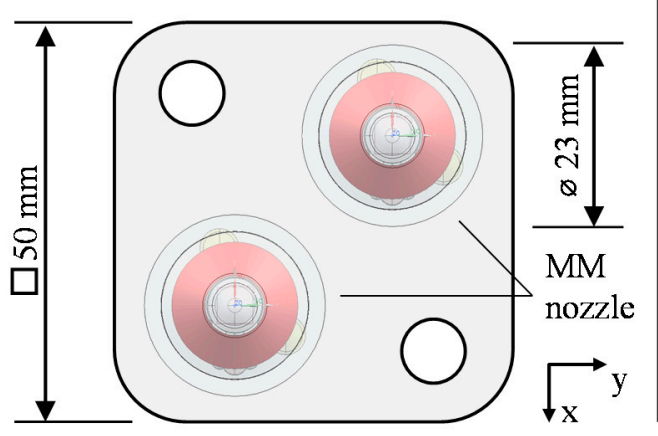

b)

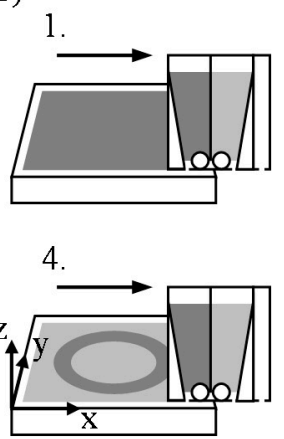

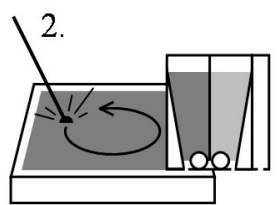

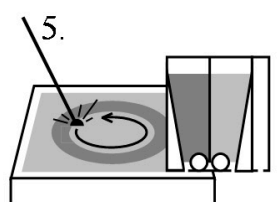

3
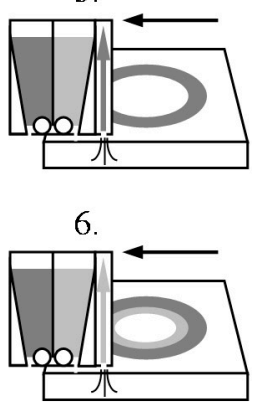

Figure 2. (a) Build job "Multi-Material Nozzle", (b) Steps of the PBF-LB/M multi-material process.

The PBF-LB/M system used for part manufacturing was an SLM 250 ${ }^{\mathrm{HL}}$ from SLM Solutions (Luebeck, Germany) equipped with an ytterbium fiber laser with a nominal 
wavelength of $1060 \mathrm{~nm}$ and a nominal spot diameter of $150 \mu \mathrm{m}$. This was extended by a suction module capable of removing and applying a secondary material in the PBF$\mathrm{LB} / \mathrm{M}$ process without process interruption $[5,12]$. The suction module for multi-materials requires the downsizing of the build space to $50 \mathrm{~mm} \times 50 \mathrm{~mm}$. The multi-material PBFLB/M process follows six steps, as shown in Figure $2 \mathrm{~b}$. At first, material A is deposited (1) and solidified (2); then, any loose powder of material A is removed by the suction module (3). Next, material B is deposited by a coater with a second chamber for material B (4) and then also solidified with the laser beam (5). Finally, any loose powder of material B is removed (6) before the process restarts on the next layer with coating of material $\mathrm{A}$.

The PBF-LB/M process parameters for tool steel (1.2709) and the copper alloy (CW106C) are listed in Table 1. Mainly spherical, gas-atomized powders with nominal particle size distributions $\left(\mathrm{d}_{10,3}-\mathrm{d}_{90,3}\right)$ of $15-45 \mu \mathrm{m}$ for the tool steel and $20-63 \mu \mathrm{m}$ for the copper alloy were used. First, the steel area on each layer was solidified, followed by the $\mathrm{Cu}$ area $[4,5,11]$. The process parameters, machine set-up, facilitated powder specification, and the overall procedure were based on Anstaett [4] and were optimized in previous studies [4,12-14].

Table 1. Process parameters.

\begin{tabular}{cccccc}
\hline \multirow{2}{*}{ Material } & $\begin{array}{c}\text { Laser } \\
\text { Power }\end{array}$ & $\begin{array}{c}\text { Scan } \\
\text { Speed }\end{array}$ & $\begin{array}{c}\text { Hatch } \\
\text { Distance }\end{array}$ & $\begin{array}{c}\text { Scan } \\
\text { Strategy }\end{array}$ & $\begin{array}{c}\text { Layer } \\
\text { Thickness }\end{array}$ \\
\cline { 2 - 6 } & $\mathbf{W}$ & $\mathbf{m m} / \mathbf{s}$ & $\mu \mathbf{m}$ & - & $\mu \mathbf{m}$ \\
\hline Steel (1.2709) & 200 & 600 & 105 & Meander & 30 \\
$\mathrm{Cu}(\mathrm{CW} 106 \mathrm{C})$ & 400 & 400 & 125 & & \\
\hline
\end{tabular}

The build job was performed twice; thus, four MM nozzles (N1-N4) were built. After the PBF-LB/M process, the surface of each MM nozzle was turned and the inner needle guiding surfaces were drilled on a conventional CNC turning machine. Turning was achieved without complications and all parts were processed. The dimensions of the nozzles in as-built condition were analyzed manually utilizing a caliper gauge.

After turning, cutting, and polishing, cross-sections of the MM nozzles were analyzed by a Hitachi TM3030Plus scanning electron microscope (SEM) equipped with an energydispersive X-ray spectroscopy (EDS) module from Bruker Nano (Billerica, MA, USA), as well as an Olympus BX53M upright metallurgical light microscope. The MM PBF$\mathrm{LB} / \mathrm{M}$ process chain from the CAD model to the final part is summarized in Figure 3. All parts were successfully machined during post-processing. Upon visual inspection of the prototype components, all four nozzles were successfully manufactured. It can be concluded that the methods described in previous research for MM part generation utilizing PBF-LB/M can be applied to complex industrial applications $[2,4,5,10,39]$. 

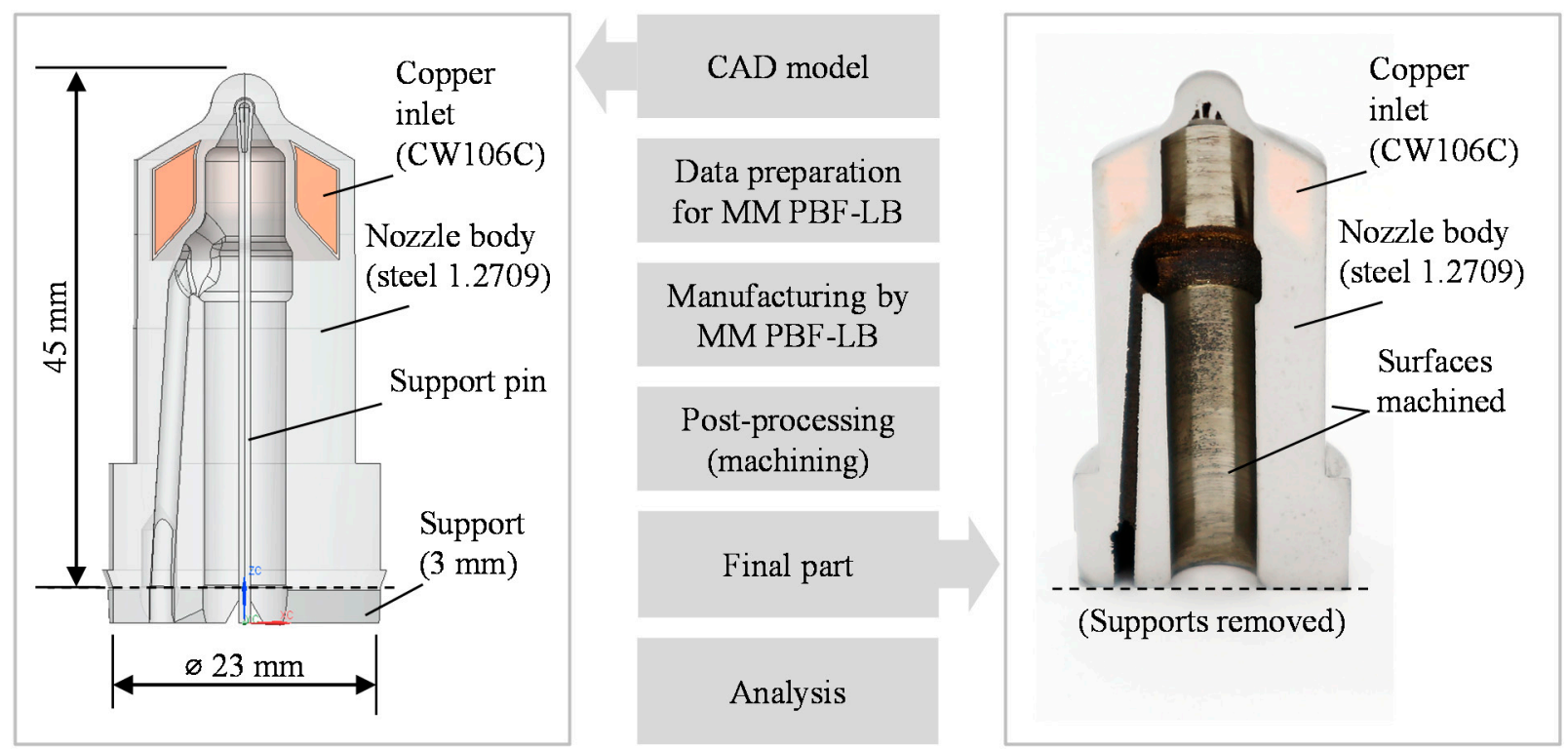

Figure 3. Process chain to manufacture the MM injection nozzle.

\section{Results and Discussion}

\subsection{Manufacturability Analysis}

In the first analysis step, the MM nozzles were measured in as-built condition and compared to the origin definition in the CAD model. The measuring protocol is displayed in Figure 4. Three heights $(\mathrm{H})$ and five diameters (D) were analyzed. Only two measures, $\mathrm{H} 1$ and H3, were undersized; all other measures were oversized, which is less relevant due to the following turning process. The undersize of $-1.75 \mathrm{~mm}$ of measure $\mathrm{H} 3$ indicated a shrinkage in the $\mathrm{z}$-direction during the MM process, but shrinkage was not confirmed by measure H2, which shows a slight oversize. Thus, it was assumed that the support of the dome at the nozzle tip was not optimal and therefore the shrinkage was only located at the nozzle tip area and was not caused by the MM process. Considering all measures apart from $\mathrm{H} 3$, the overall deviation of the MM nozzle was less than $0.3 \mathrm{~mm}$. Moreover, it can be seen that the tolerances of diameters were much lower than the deviation from the CAD model. This indicates that the deviation can be minimized by tweaking the CAD model.

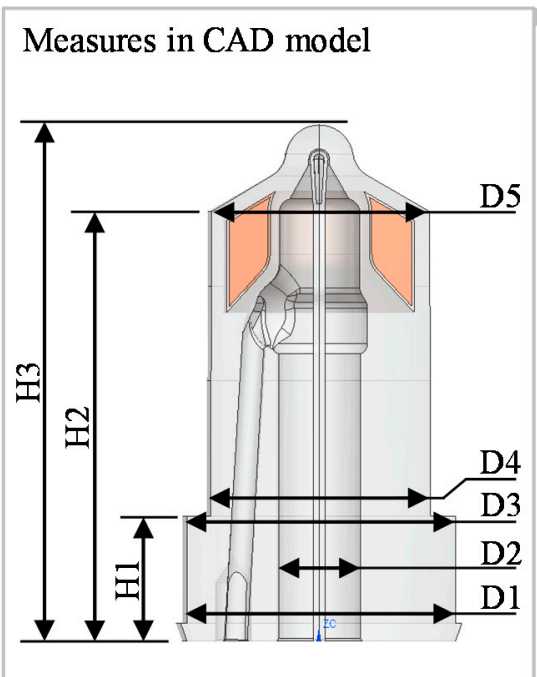

\begin{tabular}{|lrrrr}
\hline Measure & CAD & Average $^{1}$ & Tolerance $^{2}$ & Deviation \\
\hline H1 & 10.50 & 10.35 & 0.18 & -0.15 \\
H2 & 36.11 & 36.28 & 0.42 & 0.17 \\
H3 & 45.00 & 43.25 & 0.39 & -1.75 \\
\hline D1 & 23.00 & 23.26 & 0.02 & 0.26 \\
D2 & 7.00 & 6.84 & 0.02 & -0.16 \\
\hline D3 & 23.00 & 23.26 & 0.03 & 0.26 \\
\hline D4 & 18.80 & 19.04 & 0.02 & 0.24 \\
\hline D5 & 18.66 & 18.82 & 0.14 & 0.16 \\
\hline 1) Calculated from all four MM nozzles & \multicolumn{2}{|c|}{$\begin{array}{l}\text { All values } \\
\text { in mm }\end{array}$} \\
2) Tolerance = Maximum - Average & \multicolumn{4}{|c|}{. }
\end{tabular}

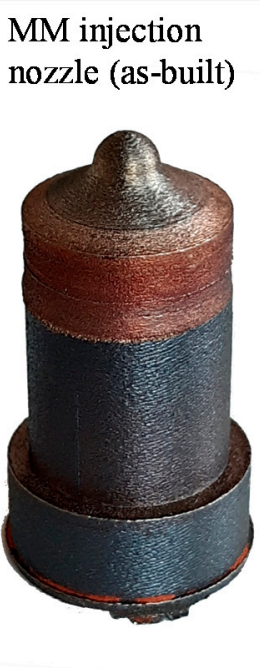

Figure 4. Measurement survey of the as-built MM injection nozzles. 


\subsection{Metallographic Characterization}

After machining, the nozzles were cut in half and cross-sections were analyzed as described in Section 2. Apart from the desired multi-material features (Figure 5, features highlighted in green), the obtained MM nozzles also showed defects, which could be categorized into six types. The defects are displayed in red in Figure 5.

1. Delamination (1a) at the start of the $\mathrm{Cu}$ area, which corresponds to the start of the MM coating process, visible at nozzle N1 and N2, and (1b) within the $\mathrm{Cu}$ area, visible at nozzle N1 and N3. It can be seen that the delamination propagated between the $\mathrm{Cu}$ and Fe area; see Figure 5, N1.1. One of the four nozzles (nozzle N4) was manufactured without delamination.

2. Coating defects occurred in both material transition directions, specifically (2a) $\mathrm{Cu}$ in steel area and (2b) steel in $\mathrm{Cu}$ area. The defect pattern was the same among all parts in a build job, which indicates that switching of materials was not successful on a whole layer; see Figure 5, N3.1 and N4.1.

3. Vertical crack / high porosity at the start of the $\mathrm{Cu}$ area. Despite there being no delamination at nozzle N4, an internal vertical crack occurred at the start of the Cu area between the steel and the $\mathrm{Cu}$ volume. Since the crack was visible on both sides of the nozzle (see Figure 5, N4.1), it was estimated that the defect had a ring shape. In comparison, this area showed high porosity at nozzle N3, but no continuous crack.

4. Porosity in transition area was visible, which was likely caused by the combination of the materials. In the presented study, the transition area had no specific process parameter set.

5. Vertical cracks occurred in the steel area. The cracks were vertically oriented along the $\mathrm{Cu}$ area in the thin wall of the steel shell.

6. Cross-contamination, (6a) even in areas with proper MM coating function, and (6b) accumulation of CW106C at steel down skin surfaces. The cross-contamination of the $\mathrm{Cu}$ alloy in the steel area was higher on average than the contamination of steel in the CW106C area, which became apparent from EDX analysis (see Figure 5, N4.4, N4.5, and Table 2).

Table 2. Element and material composition of the details highlighted in Figure 5, N4.4 and N4.5, measured via SEM EDS. * calculated.

\begin{tabular}{ccccc}
\hline Composition & Detail A & Detail B & Detail C & Detail D \\
\hline \multicolumn{5}{c}{ wt.\% } \\
\hline $\mathrm{Fe}$ & 5.51 & 1.97 & 61.31 & 62.95 \\
$\mathrm{Ni}$ & 1.50 & 0.38 & 16.26 & 16.36 \\
$\mathrm{Co}$ & 0.71 & 0.17 & 9.28 & 9.28 \\
$\mathrm{Mo}$ & 0.42 & 0.08 & 4.28 & 4.54 \\
$\mathrm{Ti}$ & 0.08 & 0.05 & 1.12 & 1.01 \\
\hline $1.2709{ }^{*}$ & 8.22 & 2.65 & 92.25 & 94.14 \\
$\mathrm{Cu}$ & 91.08 & 97.60 & 7.63 & 5.80 \\
$\mathrm{Cr}$ & 0.61 & 0.64 & 0.12 & 0.06 \\
$\mathrm{Zr}$ & 0.09 & 0.00 & 0.00 & 0.00 \\
\hline $\mathrm{CW} 106 \mathrm{C}^{*}$ & 91.78 & 98.24 & 7.75 & 5.86 \\
\hline
\end{tabular}




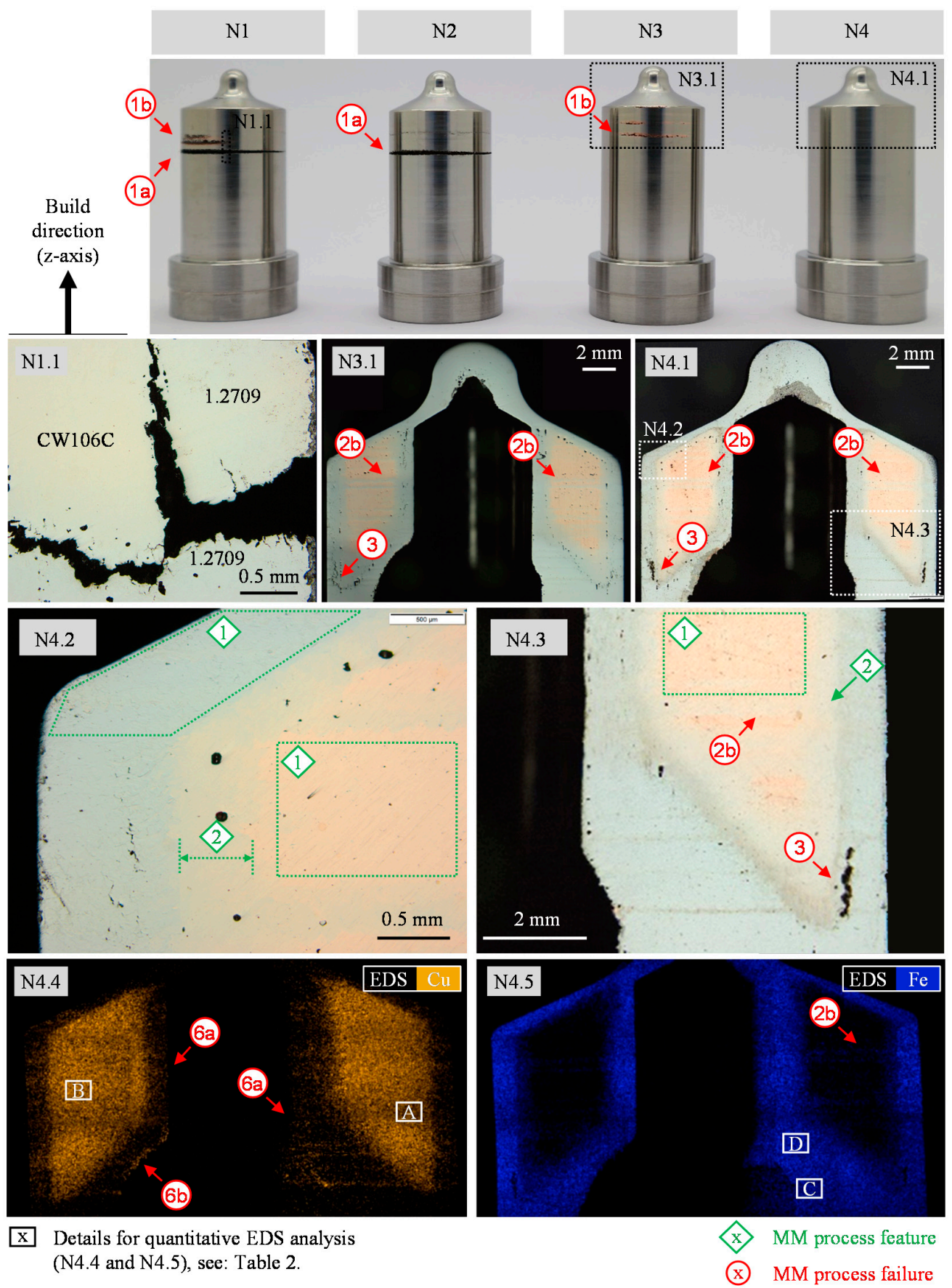

Figure 5. Analysis and defect characterization of multi-material nozzles. (N4.4 and N4.5), see Table 2.

In order to differentiate between the material zones and to better understand the formation of different types of defects, optical porosity analysis was conducted. Figure 6 depicts mean values for the different material zones from three different nozzles, resulting in a total of six measurements. Error bars depict standard errors. Values for the steel area several millimeters below the copper inlet are omitted due to their irrelevance to this study. Material densities above $99.5 \%$, however, indicate suitable process parameters. The steel area in the MM zone, in contrast, showed high porosity and high standard errors. Mostly vertical and large cracks contributed to the low material density. The transition zone had a density of $98.8 \%$ and contained mostly spherical gas pores. Porosity levels in the $\mathrm{Cu}$ area were comparable to mono-material process results on this machine [4]. 

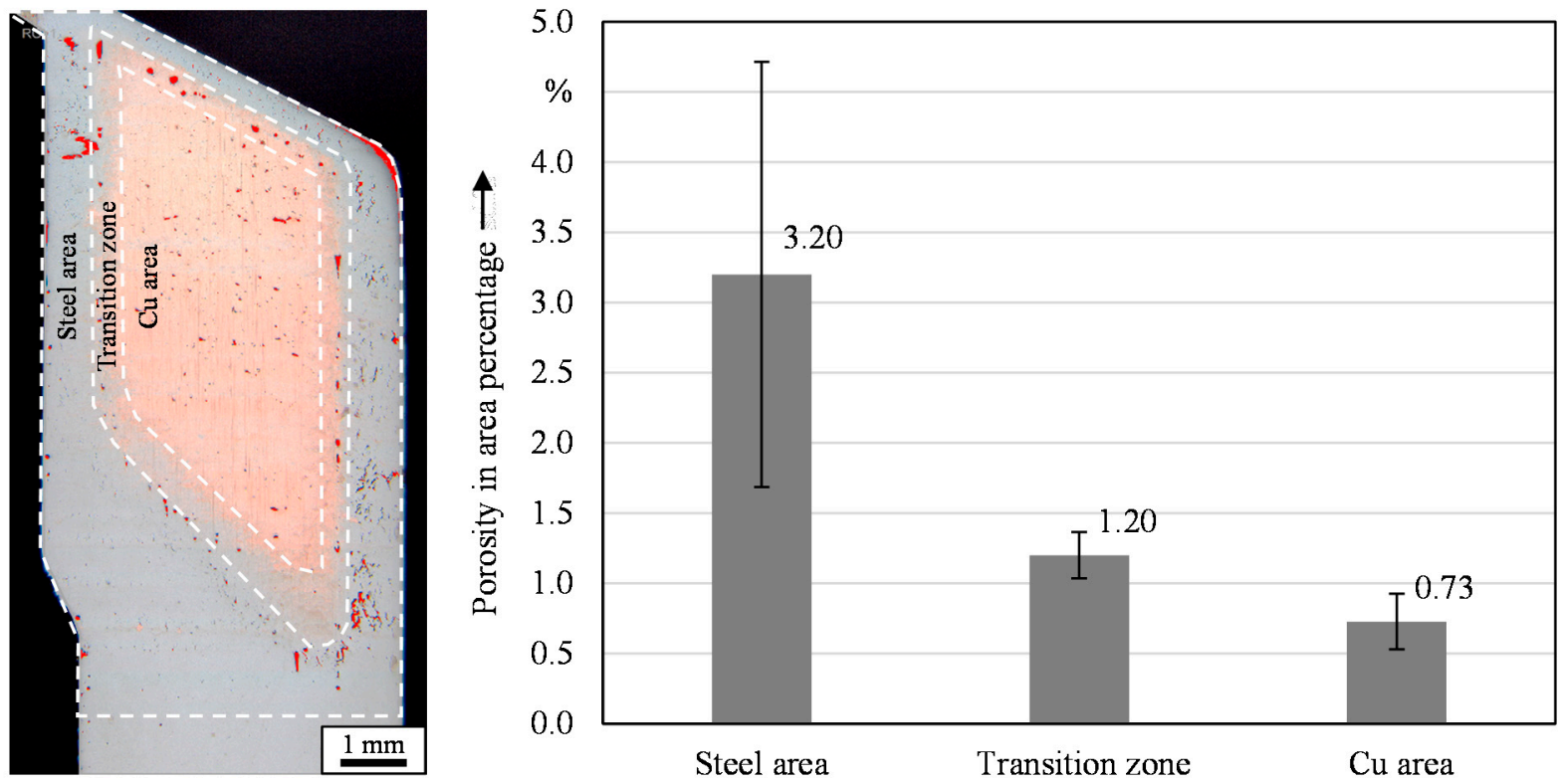

Figure 6. Porosity analysis for the different material zones. Analyzed defects are colored red in the left example image.

Since most defects appeared to be related to imperfect material deposition, the level of cross-contamination was approximated by quantitative EDS analysis (see Table 2). Four exemplary details were chosen to describe variances in material composition (see Figure 5, white details A-D in N4.4 and N4.5): CW106C regions with high (A) and low (B) steel percentage, as well as steel regions with high (C) and low (D) CW106C percentage. $\mathrm{Cu}$, $\mathrm{Cr}$, as well as $\mathrm{Zr}$ were measured for the copper alloy, and $\mathrm{Fe}, \mathrm{Ni}, \mathrm{Co}, \mathrm{Mo}$, as well as $\mathrm{Ti}$, were measured for the tool steel. Since the percentage of $\mathrm{Cr}$ in 1.2709 is below 0.25 weight percent (wt.\%), it was neglected and fully attributed to the copper alloy. Results indicate that higher material purity was achieved for the copper regions. The steel part of the component contained $\mathrm{Cu}$ alloy contamination above the purity threshold described by Horn et al. to secure material integrity [26].

\subsection{Defect Formation and Mitigation}

As described in the previous sections, the $\mathrm{Cu}$ area was comparable to results from mono-material processes in terms of porosity. Foreign particles and cross-contaminations from imperfect powder deposition either formed discrete inclusions or mixed material regions, without the occurrence of significant amounts of cracks and pores. Therefore, optimized powder deposition should prevent the observed defects and yield the desired level of material integrity.

In contrast to the $\mathrm{Cu}$ area, the transition zone contained a large number of spherical pores for the side- and upskin. The downskin of the transition zone contained only a small number of defects, which were rather located in the steel area. The sphericity of the pores indicated that gas was trapped in the melt pool, e.g., due to keyhole melting and excessively high energy input. The volumetric energy density (VED) used to melt the copper alloy was more than 2.5 times the VED used for steel. Thus, steel could vaporize and gas might have been trapped in the melt pool, creating the observed porosity. However, the fact that more pores were located at the upskin than at the downskin of the $\mathrm{Cu}$ area contradicts this thesis to some extent. Regarding this type of defect, however, an optimized scan strategy for the transition zone could be beneficial $[5,39]$ and should be the focus of future investigations.

The predominant defects in the steel area around the copper inlet were mostly vertical cracks, which accumulated in some cases and formed major voids. As the defects only occurred in the multi-material region of the nozzles, an increased copper concentration in the steel melt pool could lead to discrete liquid copper accumulations at emerging steel 
grain boundaries during solidification $[20,21,24,25]$. Thus, defects are likely to be hot cracks due to foreign particles [26], which appear to cause larger defects (Figure 5, defect no. 3) and delamination (Figure 5, defect no. $1 \mathrm{a}$ and $1 \mathrm{~b}$ ) if the $\mathrm{Cu}$ concentration is too high or forms a continuous Cu-rich layer (Figure 5, N 4.3, bottom of the copper inlet). Therefore, optimized powder deposition should increase material integrity for the steel area.

In general, the only type of defect that cannot be directly related to imperfect powder deposition is the increased porosity in the transition zone. All other defects are likely to be minimized by optimizing the powder deposition and thus decreasing the level of cross-contamination. The latter should be the focus of future hardware optimizations.

\section{Conclusions and Outlook}

In conclusion, this study shows that complex multi-material parts can be manufactured by PBF-LB/M using methods already described in the literature. As the demonstrator component, four injection nozzles with integrated copper inlets were designed and manufactured. It was shown that material quality comparable to the mono-material can be obtained if the MM process functions properly. Moreover, a geometrically defined transition zone of the materials was achieved.

Aside from the geometrical accuracy of $<0.3 \mathrm{~mm}$, the detailed analysis of the MM nozzles revealed the following desired technology features, which are highlighted in green in Figure 5:

1. Quality comparable to mono-material parts that are manufactured by a PBF-LB/M system without MM capabilities. This is valid for the steel apart from the MM section, but especially for steel and $\mathrm{Cu}$ in areas where the MM process worked without failure (see Figure 5, N4.2).

2. Geometrically specified transition area between the materials is visible. As defined in the CAD model of the part, a geometrically defined transition area of $400 \mu \mathrm{m}$ was obtained by the MM process (see Figure 5, N4.2).

3. Machining of the parts is possible without limitations. Thus, the components yielded a material quality suitable for post-processing by machining.

The analysis of the MM nozzles, however, also revealed six types of failure: delamination, coating defects, vertical cracks (especially at the beginning of the MM area), porosity in the transition area, vertical cracks in the steel area, and cross-contamination. As observed from the comparison of different nozzles (N3 and N4), it became apparent that the detected defects occurred on a regular basis. Moreover, there were areas of proper MM process functionality without defects. Thus, it is estimated that the detected defects can be solved by further development of the MM process in terms of scan strategies of the transition zone and powder deposition solutions. Due to the fact that complex, industrial MM parts were manufactured and the occurring defects can likely be solved by further process development, it is concluded that MM manufacturing by PBF-LB/M has matured to MRL 5-6.

Future research must be focused on eliminating cross-contamination during the process, since this impedes the generation of reliable results for further process optimization. Advanced, holohedral deposition concepts that are currently in development appear to have the highest potential to solve the issue of cross-contamination [2,45-47]. While MM nozzles and prior research were executed on AM systems in a laboratory environment, professional AM system suppliers have announced their intent to provide multi-material capabilities in their PBF-LB/M systems [48]. Based on such professional MM-capable systems, process optimization techniques such as process parameter optimization, exposure strategies, and design adaption for MM can be applied to eliminate defects such as porosity and cracks. Once the latter has been achieved, the mechanical and thermal properties of multi-material parts should be the focus of following investigations. Therefore, heat treatment procedures suitable for the material combination must be taken into consideration and should also be addressed in upcoming studies. In order for MM manufacturing by 
PBF-LB/M to further mature, non-destructive testing methods also need to be qualified for industrial applications.

Author Contributions: M.S. (Matthias Schneck): Conceptualization, Writing-Original Draft; M.H.: Investigation, Writing—Original Draft; M.S. (Maik Schindler): Investigation, Resources; C.S.: Writing—Review and Editing. All authors have read and agreed to the published version of the manuscript.

Funding: The authors honor the German Free State of Bavaria and its Bavarian Ministry of Economic Affairs, Energy and Technology for funding the "MULTIMATERIALZENTRUM Augsburg".

Institutional Review Board Statement: Not applicable.

Informed Consent Statement: Not applicable.

Data Availability Statement: Not applicable.

Acknowledgments: The authors express their sincere thanks to MAN Energy Solutions in Augsburg for providing valuable insights and data for injection nozzles in large bore engines. The authors also thank Regina Poetzinger for her support during image processing.

Conflicts of Interest: The authors declare no conflict of interest.

\section{References}

1. DIN EN ISO/ASTM 52921:2017-01, Normbegrifflichkeiten für Die Additive Fertigung_Koordinatensysteme und Prüfmethodologien (ISO/ASTM 52921:2013); Deutsche Fassung EN_ISO/ASTM 52921:2016; Beuth: Berlin, Germany, 2016.

2. Schneck, M.; Horn, M.; Schmitt, M.; Seidel, C.; Schlick, G.; Reinhart, G. Review on additive hybrid- and multi-materialmanufacturing of metals by powder bed fusion: State of technology and development potential. Prog. Addit. Manuf. 2021, 6, 881-894. [CrossRef]

3. Department of Defence. Manufacturing Readiness Level (MRL) Deskbook. 2018. Available online: http://www.dodmrl.com/ (accessed on 19 October 2017).

4. Anstaett, C. Multimaterialverarbeitung Mittels Laserstrahlschmelzen am Beispiel von Metallischen Verbindungen mit der Kupferlegierung CW106C. Ph.D. Thesis, Techische Universität München, Munich, Germany, 2020.

5. Wei, C.; Li, L.; Zhang, X.; Chueh, Y.-H. 3D printing of multiple metallic materials via modified selective laser melting. CIRP Ann. 2018, 67, 245-248. [CrossRef]

6. Al-Jamal, O.; Hinduja, S.; Li, L. Characteristics of the bond in $\mathrm{Cu}-\mathrm{H} 13$ tool steel parts fabricated using SLM. CIRP Ann. 2008, 57, 239-242. [CrossRef]

7. Chivel, Y. New Approach to Multi-material Processing in Selective Laser Melting. Phys. Procedia 2016, 83, 891-898. [CrossRef]

8. Binder, M.; Illgner, M.; Anstaett, C.; Kindermann, P.; Kirchbichler, L.; Seidel, C. Automated Manufacturing of Sensor-Monitored Parts. Laser Tech. J. 2018, 15, 36-39. [CrossRef]

9. Wei, C.; Sun, Z.; Chen, Q.; Liu, Z.; Li, L. Additive Manufacturing of Horizontal and 3D Functionally Graded 316L/Cu10Sn Components via Multiple Material Selective Laser Melting. J. Manuf. Sci. Eng. 2019, 141, 081014. [CrossRef]

10. Girnth, S.; Koopmann, J.; Klawitter, G.; Waldt, N.; Niendorf, T. 3D hybrid-material processing in selective laser melting: Implementation of a selective coating system. Prog. Addit. Manuf. 2019, 4, 399-409. [CrossRef]

11. Koopmann, J. Multimaterialdruck von Integrierten Elektrischen Strukturen Mittels Selektivem Laserschmelzen. Ph.D. Thesis, Kassel University Press, Kassel, Germany, 2019.

12. Anstaett, C.; Seidel, C.; Reinhart, G. Herstellung von 3-D-Multimaterialbauteilen aus Kupfer-Chrom-Zirkonium und Werkzeugstahl 1.2709. In Rapid.Tech + FabCon 3.D, Proceedings of the International Trade Show E Conference for Additive Manufacturing, Proceedings of the 15th Rapid.Tech Conference, Erfurt, Germany, 5-7 June 2018; Kynast, M., Eichmann, M., Witt, G., Eds.; Hanser: München, Germany, 2018; pp. 330-344.

13. Anstaett, C.; Seidel, C.; Reinhart, G. Fabrication of 3D-Multi-Material Parts by Laser Beam Based Powder Bed Fusion. Solid Free. Fabr. Proc. 2017, 2017, 1548-1556.

14. Anstaett, C.; Seidel, C.; Reinhart, G. Multi-Material Fabrication of Copper-Chrome-Zirconia and Tool Steel 1.2709 by Powder Bed Based Laser Beam Melting. In Proceedings of the Conference: Lasers in Manufacturing 2019, Munich, Germany; 2016; pp. 14-15. Available online: https://www.researchgate.net/publication/348167253_Metal_powder_cross-contaminations_ in_multi-material_laser_powder_bed_fusion_Influence_of_CuCr1Zr_particles_in_AlSi10Mg_feedstock_on_part_properties (accessed on 15 November 2021).

15. Zhang, X.; Wei, C.; Chueh, Y.-H.; Li, L. An Integrated Dual Ultrasonic Selective Powder Dispensing Platform for ThreeDimensional Printing of Multiple Material Metal/Glass Objects in Selective Laser Melting. J. Manuf. Sci. Eng. 2018, 141, 011003. [CrossRef]

16. Ott, M. Multimaterialverarbeitung bei der Additiven Strahl- und Pulverbettbasierten Fertigung, Iwb. Ph.D. Thesis, Techische Universität München, Munich, Germany, 2012. 
17. Koopmann, J.; Voigt, J.; Niendorf, T. Additive Manufacturing of a Steel-Ceramic Multi-Material by Selective Laser Melting. Met. Mater. Trans. A 2019, 50, 1042-1051. [CrossRef]

18. Weißbach, W. Werkstoffkunde: Strukturen, Eigenschaften, Prüfung, 17th ed.; Vieweg + Teubner: Wiesbaden, Germany, 2010.

19. Phanikumar, G.; Manjini, S.; Dutta, P.; Chattopadhyay, K.; Mazumder, J. Characterization of a continuous CO2 laser-welded Fe-Cu dissimilar couple. Met. Mater. Trans. A 2005, 36, 2137-2147. [CrossRef]

20. Munitz, A. Liquid separation effects in $\mathrm{Fe}-\mathrm{Cu}$ alloys solidified under different cooling rates. Met. Mater. Trans. A 1987, 18, 565-575. [CrossRef]

21. Kauss, N.; Halle, T.; Rosemann, P. Age-hardening behaviour, microstructure and corrosion resistance of the copper alloyed stainless steel 1.4542. IOP Conf. Series Mater. Sci. Eng. 2018, 373, 012020. [CrossRef]

22. Lu, X.; Cao, C.; Wei, B. Microstructure evolution of undercooled iron-copper hypoperitectic alloy. Mater. Sci. Eng. A 2001, 313, 198-206. [CrossRef]

23. Chen, S.; Huang, J.; Xia, J.; Zhang, H.; Zhao, X. Microstructural Characteristics of a Stainless Steel/Copper Dissimilar Joint Made by Laser Welding. Met. Mater. Trans. A 2013, 44, 3690-3696. [CrossRef]

24. Yao, C.; Xu, B.; Zhang, X.; Huang, J.; Fu, J.; Wu, Y. Interface microstructure and mechanical properties of laser welding copper-steel dissimilar joint. Opt. Lasers Eng. 2009, 47, 807-814. [CrossRef]

25. Mai, T.; Spowage, A. Characterisation of dissimilar joints in laser welding of steel-kovar, copper-steel and copper-aluminium Mater. Sci. Eng. A 2004, 374, 224-233. [CrossRef]

26. Horn, M.; Langer, L.; Schafnitzel, M.; Dietrich, S.; Schlick, G.; Seidel, C.; Reinhart, G. Influence of Metal Powder CrossContaminations on Part Quality in Laser Powder Bed Fusion: Copper Alloy Particles in Maraging Steel Feedstock. Procedia CIRP 2020, 94, 167-172. [CrossRef]

27. Mahamood, R.M.; Akinlabi, E.T.; Shukla, M.; Pityana, S. Functionally Graded Material: An Overview. In Proceedings of the 2012 International Conference of Manufacturing Engineering and Engineering Management, the 2012 International Conference of Mechanical Engineering, London, UK, 4-6 July 2012; Imperial College London: London, UK, 2012; Volume III.

28. Pei, E.; Loh, G.H.; Harrison, D.; Almeida, H.D.A.; Verona, M.D.M.; Paz, R. A study of 4D printing and functionally graded additive manufacturing. Assem. Autom. 2017, 37, 147-153. [CrossRef]

29. Popov, V.V.; Fleisher, A. Hybrid additive manufacturing of steels and alloys. Manuf. Rev. 2020, 7, 6. [CrossRef]

30. El-Galy, I.M.; Saleh, B.I.; Ahmed, M.H. Functionally graded materials classifications and development trends from industrial point of view. SN Appl. Sci. 2019, 1, 1378. [CrossRef]

31. Tan, C.; Chew, Y.; Bi, G.; Wang, D.; Ma, W.; Yang, Y.; Zhou, K. Additive manufacturing of steel-copper functionally graded material with ultrahigh bonding strength. J. Mater. Sci. Technol. 2020, 72, 217-222. [CrossRef]

32. Santos, L.M.S.; De Jesus, J.; Ferreira, J.M.; Costa, J.; Capela, C. Fracture Toughness of Hybrid Components with Selective Laser Melting 18Ni300 Steel Parts. Appl. Sci. 2018, 8, 1879. [CrossRef]

33. Wallis, C.; Buchmayr, B.; Kitzmantel, M.; Brandstätter, E. Additive Manufacturing of Maragin Steel on a Copper Substrate using Selective Laser Melting. In Proceedings of the 2nd Metal Additive Manufacturing Conference 2016-MAMC 2016, Linz, Austria, 24-25 November 2016.

34. Yeong, W.Y.; Chen, S. Selective Laser Melting of Copper Based Alloy on Steel: A Preliminary Study. In Proceedings of the 2nd International Conference on Progress in Additive Manufacturing (Pro-AM 2016), Nanyang Technological University, Singapore, 16-19 May 2016.

35. Chen, J.; Yang, Y.; Wang, D.; Liu, Z.; Song, C. Effect of manufacturing steps on the interfacial defects of laser powder bed fusion 316L/CuSn10. Mater. Lett. 2021, 292, 129377. [CrossRef]

36. Chueh, Y.-H.; Wei, C.; Zhang, X.; Li, L. Integrated laser-based powder bed fusion and fused filament fabrication for threedimensional printing of hybrid metal/polymer objects. Addit. Manuf. 2019, 31, 100928. [CrossRef]

37. Chueh, Y.-H.; Zhang, X.; Ke, J.C.-R.; Li, Q.; Wei, C.; Li, L. Additive manufacturing of hybrid metal/polymer objects via multiple-material laser powder bed fusion. Addit. Manuf. 2020, 36, 101465. [CrossRef]

38. Liu, Z.; Zhang, D.; Sing, S.; Chua, C.; Loh, L. Interfacial characterization of SLM parts in multi-material processing: Metallurgical diffusion between 316L stainless steel and C18400 copper alloy. Mater. Charact. 2014, 94, 116-125. [CrossRef]

39. Binder, M. Potentials and Challenges of Multi-Material Processing by Laser-Based Powder Bed Fusion. In Proceedings of the 29th Annual International Solid Freeform Fabrication Symposium 2018, Austin, TX, USA, 13-15 August 2018; pp. 376-387.

40. Oelschlegel, H.J. Dieselmotorische Verbrennung. In Springer Reference Technik, Handbuch Dieselmotoren; Tschöke, H., Mollenhauer, K., Maier, R., Eds.; Springer Fachmedien: Wiesbaden, Germany, 2018; pp. 91-116.

41. Zeh, D.; Okumuşoğlu, A. Einspritzdüsen und Düsenhalter für Diesel-Einspritzsysteme. In Springer Reference Technik, Handbuch Dieselmotoren; Tschöke, H., Mollenhauer, K., Maier, R., Eds.; Springer Fachmedien: Wiesbaden, Germany, 2018 ; pp. $299-307$.

42. Gradl, P.R.; Teasley, T.W.; Protz, C.S.; Garcia, M.B.; Ellis, D.; Kantzos, C. Advancing GRCop-based Bimetallic Additive Manufacturing to Optimize Component Design and Applications for Liquid Rocket Engines. AIAA Propuls. Energy 2021. [CrossRef]

43. Walker, J.; Middendorf, J.R.; Lesko, C.C.; Gockel, J. Multi-material laser powder bed fusion additive manufacturing in 3dimensions. Manuf. Lett. 2021. [CrossRef]

44. Wei, C.; Li, L. Recent progress and scientific challenges in multi-material additive manufacturing via laser-based powder bed fusion. Virtual Phys. Prototyp. 2021, 16, 347-371. [CrossRef] 
45. Aerosint. How Multi-Powder Deposition will Transform Industrial 3D Printing. 2018. Available online: https://aerosint.com/ powder-deposition-multimaterial-printing/ (accessed on 15 September 2021).

46. Förster, J.; Wunderer, M.; Michatz, M.; Anstätt, C.; Seidel, C.; Schilp, J. Entwicklung eines elektrofotografischen Pulverapplikationsmoduls für laserbasierte Pulverbettschmelzverfahren-Ladungserhalt und Entladung eines Fotoleiters durch Umgebungsbeleuchtung. In Proceedings of the 17th Rapid.Tech 3D Conference, Erfurt, Germany, 22-23 June 2021; Kynast, M., Witt, G., Eichmann, M., Eds.; Carl Hanser Verlag GmbH \& Co. KG: München, Germany, 2021; pp. 235-244.

47. Foerster, J.; Michatz, M.; Anstaett, C.; Seidel, C.; Schilp, J. Aspects of Developing a Powder Application Module Based on Electrophotography for Additive Powder Bed Based Processes. SSRN J. 2020, 147-152. [CrossRef]

48. SLM Solutions AG. Product Description SLM 280 2.0. Available online: https://www.slm-solutions.com/products-and-solutions / machines/slm-280/ (accessed on 15 September 2021). 